\title{
Commercial Evaluation of a Continuous Micronutrient Fortification Process for Nixtamal Tortillas
}

\author{
Michael L. Dunn \\ michael_dunn@byu.edu \\ Sergio 0. Serna-Saldivar \\ Diana Sanchez-Hernandez \\ Robert W. Griffin
}

Follow this and additional works at: https://scholarsarchive.byu.edu/facpub

Part of the Food Science Commons, and the Nutrition Commons

\section{Original Publication Citation}

Dunn, M.L., Serna, S.S.O, Sanchez-Hernandez, D. and Griffin, R.W. "Commercial Evaluation of a Continuous Micronutrient Fortification Process for Nixtamal Tortillas." Cereal Chemistry. 85.6 (28): 746-752.

\section{BYU ScholarsArchive Citation}

Dunn, Michael L.; Serna-Saldivar, Sergio O.; Sanchez-Hernandez, Diana; and Griffin, Robert W., "Commercial Evaluation of a Continuous Micronutrient Fortification Process for Nixtamal Tortillas" (2008). Faculty Publications. 154.

https://scholarsarchive.byu.edu/facpub/154

This Peer-Reviewed Article is brought to you for free and open access by BYU ScholarsArchive. It has been accepted for inclusion in Faculty Publications by an authorized administrator of BYU ScholarsArchive. For more information, please contact ellen_amatangelo@byu.edu. 


\title{
Commercial Evaluation of a Continuous Micronutrient Fortification Process for Nixtamal Tortillas
}

\author{
Michael L. Dunn, ${ }^{1,2}$ Sergio O. Serna-Saldivar, ${ }^{3}$ Diana Sanchez-Hernandez, ${ }^{4}$ and Robert W. Griffin ${ }^{5}$
}

The corn tortilla plays an integral role in the Mexican diet and is an ideal vehicle for micronutrient fortification. Approximately $60 \%$ of corn tortillas in Mexico are produced from nixtamal, with the remainder prepared from masa flour. A process for continuous fortification of nixtamal tortillas was evaluated in two commercial mills in Mexico. A commercial powder dosifier was used to add micronutrient premix containing iron, zinc, folic acid, niacin, riboflavin, and thiamin to nixtamal $(1 \mathrm{~g} / \mathrm{kg})$ as it was milled. After training and preliminary sampling, mills produced fortified tortillas unassisted for four weeks. Masa flow rates over a four-day period were $10-12 \mathrm{~kg} / \mathrm{min}$ in both plants. Premix flow from the dosifier showed good stability, with an average coefficient of variation of $1.6 \%$. Initial results indicated consistency in the fortification process, with significantly increased variation during the four-week production period. Fortified tortillas had significantly higher levels of all nutrients tested. Micronutrient losses were $<11 \%$ in all cases except folic acid, which showed an $80 \%$ loss. Despite processing losses, fortification resulted in a nearly fivefold increase in folic acid compared with control tortillas. The new fortification process is technically viable and was well received by millers.
The corn tortilla plays an integral role in the diet of most Mexicans. It is estimated that, in rural areas of Mexico, $65 \%$ of dietary nutrients come from tortillas and related products and $15 \%$ from beans (Figueroa et al 2003). On average, corn tortillas are the largest contributor to individual energy intake among Mexicans (Shamah Levy et al 2003). Due to the very high consumption rates in Mexico, corn tortillas are ideal vehicles for micronutrient fortification and enrichment, with a particularly high likelihood of reaching populations most likely to suffer from micronutrient deficiencies.

Corn tortillas are made directly from fresh nixtamal, from nixtamalized masa flour, or a combination of the two. Dry flour fortification technology has been used globally with great success; however, the majority of corn tortillas consumed in Mexico are made from wet-milled nixtamal rather than dry masa flour, leaving a large number of Mexicans effectively beyond the reach of current cereal fortification technology (unpublished data). Development of an industrial process for fortification of nixtamal tortillas would extend the benefits of micronutrient enrichment to a much larger segment of the population.

Although several researchers have previously conducted fortification trials with corn tortillas, these have been either masa flour tortillas or nixtamal tortillas prepared in small-scale laboratory experiments or limited nonproduction trials in commercial mills (Figueroa 1999; Rosado et al 1999, 2005; Figueroa et al 2003; Tovar and Larios-Saldaña 2005). There remains a critical need to build on this previous experience and develop a viable commercial process that can be used to fortify nixtamal tortillas in a representative, semicontinuous production setting.

The authors recently described a commercial process for the micronutrient fortification of tortillas prepared by wet milling fresh nixtamal (Dunn et al 2007). After extensive consideration of all of the potential fortification methodologies that might be used,

\footnotetext{
${ }^{1}$ Associate Professor Food Science, Brigham Young University, S-221 ESC, Provo, UT 84602.

${ }^{2}$ Corresponding author. Phone: 1-801-422-6670. Fax: 1-801-422-0258. E-mail: michael_dunn@byu.edu

${ }^{3}$ Professor, Department of Biotechnology and Food Engineering, Tecnológico de Monterrey, Av. Eugenio Garza Sada 2501, 64849 Monterrey, N.L., México.

${ }^{4}$ Department of Biotechnology and Food Engineering, Tecnológico de Monterrey, Av. Eugenio Garza Sada 2501, 64849 Monterrey, N.L., México.

${ }^{5}$ R.W. Griffin \& Associates, 2162 Cascade Lakes Circle, SE, Suite 326, Grand Rapids, MI 49546.
}

doi:10.1094/CCHEM-85-6-0746

(c) 2008 AACC International, Inc. the best approach for enrichment of industrially prepared nixtamal tortillas was determined to be a dosification system that incorporates a micronutrient premix powder into the nixtamal feed stream as it passes into the grinding stones during milling. This article presents results of an evaluation of enrichment homogeneity and vitamin retention during semicontinuous commercial production of micronutrient-fortified, nixtamal tortillas in two different mills in Mexico.

\section{MATERIALS AND METHODS}

\section{Commercial Mills}

Two nixtamal/tortilla mills were selected for commercial production, one in Mexico City (plant 1) and another in Guadalajara, Jalisco (plant 2). Each mill produced 1,800-2,000 kg of masa per day in a series of three to four production runs of $\approx 60-90 \mathrm{~min}$ in duration, followed by several very short production runs later in the day as demand required. Both plants produced tortillas on site and also supplied masa for several other tortillerias.

\section{Materials}

A micronutrient premix in dry powder form was provided by DSM Nutritional Products, Mexico S.A. de C.V. (Mexico, DF). Premix composition was based on vitamin and mineral addition levels proposed by COFEPRIS for enrichment of corn flour (Secretaria de Salud 2005) with adjustments made to account for the higher moisture content of nixtamal (Table I). The premix included a maltodextrin carrier that was incorporated to allow dosing of $1 \mathrm{~g}$ of premix per kilogram of masa, as well as $0.1 \%$ silicon dioxide as a flow agent. A-131 electrolytic iron $(4.72 \% \mathrm{w} / \mathrm{w}$ in premix), zinc oxide $(2.91 \%)$, nicotinamide $(2.02 \%)$, thiamin mononitrate $(0.36 \%)$, riboflavin $(0.17 \%)$, and folic acid $(0.13 \%)$ were used as micronutrient sources. A single lot of premix was prepared by DSM and used in both mills participating in the study. Mineral evaluation of premix across individual boxes within the shipment showed good homogeneity; and external laboratory analyses indicated conformity with the target micronutrient specifications (Table I).

Both mills used white dent corn for nixtamalization. Plant 1 used bagged white corn from Cargill de Mexico SA de CV (Mexico, D.F.) with a thousand-kernel weight average of $387 \mathrm{~g}$, whereas plant 2 used bulk corn from a local broker with a thousand-kernel weight average of $370 \mathrm{~g}$. Both lots of corn represent the preferred type used by the Mexican tortilla industry and had an intermediate endosperm texture with $\approx 50 \%$ floury or chalky endosperm and $50 \%$ hard or corneous endosperm. 


\section{Micronutrient Premix Addition}

Premix dosing into nixtamal was accomplished using a powder dosifier (Probst, SA de CV, Mexico, D.F.) that deposited premix at a constant rate directly onto the nixtamal feed stream just as it passed into the millstones. The correct premix dosage was achieved by measuring the masa (in $\mathrm{kg}$ ) produced by the individual grinding $\mathrm{mill} / \mathrm{min}$ and then adjusting the dosifier flow rate to dispense that amount of premix $(\mathrm{g} / \mathrm{min})$. Mill and dosifier flow rates were checked at the beginning of each production run during a day, with periodic checks made at regular intervals to monitor dosing consistency. Adjustments were made as needed to compensate for flow rate changes caused by wear on the stones.

\section{Masa and Tortilla Production}

Plant 1. Corn $(700 \mathrm{~kg})$ was added to hot water $(\approx 2,000 \mathrm{~L})$ in the cook tank, along with $8.4 \mathrm{~kg}$ of lime $(1.2 \%)$. The corn was cooked for $15 \mathrm{~min}$ at $95^{\circ} \mathrm{C}$ before transferring to a steep tank, where it was held overnight (typically 12-14 hr). Steeped corn was drawn into the wash-hopper as needed, where it was drained and washed lightly with water. Due to local preference, a small amount of additional lime was sprinkled on top of the washed nixtamal before transferring to the mill hopper using an elevated auger. The light wash and extra lime addition yielded a creamy yellow tortilla. The mill hopper had a v-shaped, rectangular design with a helical screw auger running lengthwise along the base of the hopper to feed the volcanic millstones. In this mill design, the feed auger running along the bottom of the mill hopper is typically buried under the mass of nixtamal transferred from the wash-hopper. To allow deposition of premix, a perpendicular wall was welded across the width of the hopper to create a void space in the hopper at the end nearest the millstones. A semicircular opening in the base of the wall allowed free passage of the fully loaded auger flights. This construction provided a short length of exposed auger, loaded with nixtamal, on top of which premix was dosed as it fed into the millstones. Masa was collected in an open bell housing in 50-kg bundles, wrapped in used corn sacks, and stacked on the holding table until needed. To make tortillas, a ball of masa (3-4 kg) was placed in a small mixer (amasadora) at the side of the oven and water was added (not measured) until the dough attained the proper consistency for sheeting and forming. The masa was then placed on a tortilla roller/former with cutting dies to form the tortilla rounds. Tortillas were baked in a triplepass, gas-fired oven at $290^{\circ} \mathrm{C}$ for $\approx 50 \mathrm{sec}$. While in the oven, tortillas were inverted twice.

Plant 2. The nixtamalization process at plant 2 was similar to plant 1 . The cooking tank was filled with hot $\left(95^{\circ} \mathrm{C}\right)$ water $(\approx 1,800 \mathrm{~L})$ and then $6.6 \mathrm{~kg}$ of lime was added. Corn was transferred by elevated auger from the bulk storage room until the tank was full $(\approx 600 \mathrm{~kg})$. Heat was applied to bring the tank back up to $92^{\circ} \mathrm{C}$, after which the corn was transferred to a steep tank for 8 $12 \mathrm{hr}$. The remaining process was similar to plant 1 , except that the nixtamal was washed more extensively and no additional lime was added, due to the preference for a white tortilla. The grinding mill in plant 2 already had a short section of exposed auger extending from the base of the main mill hopper, which deposited nixtamal into a smaller hopper directly below. A short auger in the bottom of the smaller hopper fed the nixtamal into the millstones. Rather than having the typical open bell housing, the millstones in plant 2 were fully enclosed in a v-shaped housing which trapped the ground masa and fed it into an extruder auger 22-in. long which forced the masa out onto a collection table through a $20-\mathrm{cm}$ i.d. steel pipe. In plant 2, no configurational changes were made to the mill. The powder dosifier was positioned over the external auger exiting the main mill hopper. This site provided excellent exposure of the nixtamal feed stream and good mixing along the auger as well as in the small feed hopper. After milling, the masa was weighed $(20 \mathrm{~kg})$, packed in plastic buckets with lids, and stacked to one side until needed. For tortilla manufacturing, masa was transferred to a Celorio tortilla-forming machine (Maquinas Tortilladoras Celorio SA de CV, Naucalpan, México) comprising a mixer, extruder, and former in one unit. Formed tortillas were baked in a triple-pass, gas-fired oven at $300^{\circ} \mathrm{C}$ for $\approx 42 \mathrm{sec}$.

\section{Training Plant Personnel}

The first two days of production in each plant were used to train the operators and evaluate and make adjustments to the equipment. Operators were also trained on the use of a qualitycontrol sheet, which was used to record and monitor masa flow rates from the mill and premix flow rates from the dosifier at the beginning of each production run, as well as premix usage and total masa throughput for the day. A training poster was placed in each plant with illustrated step-by-step instructions for checking mill and dosifier flow rates and operation of the dosifier. Additionally, a manual providing detailed instructions regarding use of the dosifier for micronutrient fortification of fresh masa was reviewed with each mill owner and left with the mill for future reference. Project scientists continued to provide technical support for the remainder of the week but actual operation was under control of plant personnel. After this initial week of technical support, plant personnel carried out operations completely unassisted, without the presence of or participation from project scientists.

\section{Homogeneity and Stability Testing}

During the training week, samples were collected to evaluate dosing consistency and to assess vitamin stability during processing. To evaluate micronutrient homogeneity across production days, unfortified control $(\mathrm{Ct})$ and micronutrient-fortified (MF) tortilla samples $(180 \mathrm{~g})$ were collected in duplicate from each of three production runs on each of two consecutive days Tortilla samples were collected at the oven exit and were allowed to cool at room temperature for $25 \mathrm{~min}$ before placing in plastic sample bags and freezing in a small chest freezer. $\mathrm{Ct}$ samples were collected at the beginning of the day using a clean mill. To evaluate consistency within a run, $\mathrm{Ct}$ and MF tortilla samples (180 g) were

TABLE I

Micronutrient Addition Levels in Nixtamal Based on COFEPRIS Proposal for Nutrient Addition to Corn Masa Flour ${ }^{\mathrm{a}}$

\begin{tabular}{|c|c|c|c|c|}
\hline Micronutrient & Flour Addition (mg/kg) & Nixtamal Addition (mg/kg) ${ }^{b}$ & Premix Formula (g/kg) & Premix Actual (mg/kg) ${ }^{c}$ \\
\hline Iron & $40.0^{\mathrm{d}}$ & 23.11 & $46.22^{\mathrm{e}}$ & $47.46 \pm 1.70$ \\
\hline Zinc & 40.0 & 23.11 & 23.11 & $24.85 \pm 0.82$ \\
\hline Folic acid & 2.0 & 1.16 & 1.16 & $1.28 \pm 0.12$ \\
\hline Niacin & 35.0 & 20.22 & 20.22 & $20.58 \pm 0.45$ \\
\hline Riboflavin & 3.0 & 1.73 & 1.73 & $1.84 \pm 0.12$ \\
\hline Thiamin & 5.0 & 2.89 & 2.89 & $3.32 \pm 0.39$ \\
\hline
\end{tabular}

a Secretaria de Salud 2005. COFEPRIS: Comisión Federal para la Protección contra Riesgos Sanitarios.

b Conversion based on estimated average of $90 \%$ solids content in flour and $52 \%$ solids content in nixtamal.

${ }^{\mathrm{c}}$ Composition based on average analytical results from three external laboratories.

${ }^{\mathrm{d}}$ From ferrous sulfate, ferrous fumarate, or an equivalent bioavailable amount from another source.

e Electrolytic iron (46.22 mg) was used in the premix for this study to account for lower bioavailability compared with ferrous sulfate. 
collected at $\approx 10$-min intervals across separate 1 -hr production runs (six samples per run) on each of two consecutive days. Frozen samples were shipped on ice by overnight courier to the Cereal Quality and Environmental Research Laboratories of Tecnológico de Monterrey (ITESM) for moisture, sample preparation, and mineral analysis.

For evaluation of vitamin stability, two consecutive sets of $\mathrm{Ct}$ and MF masa and tortillas samples (180 g) were collected on each of two consecutive days in plant 2. Tortilla samples were handled as described above. Masa samples were collected as uncooked tortilla disks immediately upon exiting the tortilla former, placed directly in plastic sample bags, and frozen. Frozen samples were shipped on dry ice to each of two different analytical testing laboratories for vitamin, mineral, and moisture analysis. Laboratories participating in the stability study were Covance Laboratories (Madison, WI) and Medallion Laboratories (Minneapolis, MN). A third sample set was collected on one day and sent to the research laboratories of DSM for confirmatory vitamin analysis in case of discrepancies between labs. DSM results were included in the data analysis. One laboratory reported significantly different results for riboflavin and folic acid for some treatments. In this case, only the data from the other two labs were used in the final statistical analysis.

For comparative purposes, a $20-\mathrm{kg}$ bag of vitamin- and mineral-enriched commercial masa flour was obtained for each plant. Both bags of flour were of the same brand but each was from a different production lot. Six batches of masa were prepared from each bag according to the manufacturer's instructions and converted to tortillas. Tortillas were packaged, stored, and shipped to ITESM as described previously.

\section{Sampling During Commercial Production}

During the four weeks of unassisted commercial production, tortilla samples were collected once a day on alternating days of the week (three samples/week). Millers were instructed to begin each day by producing a short run of $\mathrm{Ct}$ tortillas without premix addition. After a 500-g sample of Ct tortillas was collected, production switched to fortified tortillas. Later in the day, a $500-\mathrm{g}$ sample of fortified tortillas was collected by random audit. All samples were placed in a small freezer in the mill until the end of the week, at which time they were removed and sent to ITESM for mineral analysis. This procedure was repeated for four consecutive weeks of unassisted commercial production.

\section{Analytical}

Samples sent to ITESM were analyzed for iron, zinc, and moisture content. Moisture was tested using a forced-draft oven (Approved Method 44-15, (AACC International 2000) and iron and zinc were tested by inductively coupled plasma spectroscopy (ICP) (Approved Method 40-75, AACC International 2000). Moisture values were used to allow reporting of results on a dry basis for more relevant comparisons.

Micronutrient levels in samples sent to the other external labs were determined according to official methods. Iron and zinc were determined according to AOAC method 990.08 (Medallion) and AOAC method 985.01 (Covance). Folic acid was measured according to AOAC method 960.46 (Covance) and AOAC method 2004.05 (Medallion). Riboflavin was analyzed using AOAC method 960.46 (Covance) and AOAC method 970.65 (Medallion). Thiamin was measured with AOAC method 942.23. Niacin content was determined using AOAC method 960.46. Moisture was tested according to Approved Methods 44-15A and 44-31 (AACC International 2000). All micronutrient analyses were typically completed within 14-21 days of sample collection.

\section{Statistical Analysis}

Mean values for masa and premix flow rates across plants and days and for vitamin and mineral content among $\mathrm{Ct}$ and MF masa and tortillas were compared by analysis of variance (ANOVA) using JMP (Statistical Discovery v.6.0.0; SAS Institute Cary, NC). Post hoc mean comparisons were performed using the TukeyKramer LSD. Micronutrient content in fortified tortillas was compared with theoretical levels calculated by adding target premix levels to analytical micronutrient levels in Ct masa. A significance value of $P=0.05$ was used to distinguish significant differences among treatments. Homogeneity was evaluated by comparing the magnitude of the coefficient of variation $(\mathrm{CV})$ for zinc, which was not expected to change during processing beyond the milling stage, between $\mathrm{Ct}$ and MF treatments, as well as by comparing individual data points to $95 \%$ confidence limits on either side of the mean. Confidence limits were calculated based on total variation in both plants for $\mathrm{Ct}$ and $\mathrm{MF}$ tortillas.

\section{RESULTS AND DISCUSSION}

\section{Mill and Dosifier Setup}

Although plant 1 and plant 2 both produce approximately the same amount of masa per day ( 2 metric tons), the mill design, the color and flavor of tortillas produced, and the nature of the business in each plant are substantially different. Each mill has a single mill operator who manages nixtamalization and masa production while several other employees operate the tortilla ovens and handle sales. Neither mill operator had any education beyond partial primary school, though the mill owners in both cases had college degrees.

The mill adjustments required in plant 1 were made quite readily in one afternoon after finishing production for the day and did not impact the regular production process in any way. In both cases, the mill owners designed and built a mounting stand for the dosifier so that it could be positioned over the nixtamal feed stream entering the millstones. Due to the widely varying mill configurations in different plants, the mounting stand will probably need to be custom-built for each mill adopting the technology. In plant 1 , the dosifier was mounted on a tall, stationary, fourlegged stand. In plant 2 , the stand was mounted to one of the building's I-beam supports and was designed to swivel in and out of place.

The operation of the dosifier is fairly simple, and both mill operators quickly adjusted to the additional steps of checking the mill and dosifier flow rates before starting up the mill for each production run during the day. This particular step was facilitated by the fact that the premix dosis target in $\mathrm{g} / \mathrm{min}$ was a $1: 1$ ratio with the $\mathrm{kg} / \mathrm{min}$ flow of the masa.

Both millers expected that masa flow rates would decrease somewhat as the day progressed due to wear on the surface of the millstones during grinding. The common practice in both mills was to replace the millstones each morning with newly resurfaced stones. Another factor that could cause variation in masa flow rates from run to run during the day is the requirement to manually set the millstone gap before turning on the mill each time. Before each start-up, the mill operator uses a torsion wheel to open the gap between the millstones so that the stones initially rotate freely until nixtamal begins to feed into the gap. Immediately after applying power to the mill, the operator quickly closes the gap between the stones by manually rotating the torsion wheel until he feels the pressure is correct. This adjustment is made entirely based on experience. Despite the use of different millstones each day, as well as the potential variation from the gap adjustment and the wear on the stones, Table II indicates that masa flow rates on the four days evaluated were surprisingly uniform. Another factor that could have affected masa flow rates was the initiation and termination of the grinding at the beginning and ending of a 1-min period. This was particularly complicated by the masa extrusion design in plant 2 . The masa tended to exit the extruder pipe in spurts rather than flowing steadily. It is believed that the fluctuation in mass resulting from this somewhat erratic 
flow was the reason for the greater degree of dispersion around the masa flow-rate mean in plant 2. For this reason, two to three flow rate readings were typically collected at the beginning of each run in that plant. However, even with the slightly larger standard deviation, flow rates in plant 2 were still acceptably uniform. Masa flow-rate samples were actually easier to collect in plant 2 because it was not necessary to shut off the mill at the end of the 1-min sample period. The masa exiting the extruder was merely pinched off with the hands and weighed. With the bellhousing configuration in plant 1 , the mill had to be started and stopped at the beginning and end of the 1-min collection period and then the masa was gathered and weighed. For this reason, typically only one or two readings were taken for each production run in plant 1. ANOVA results indicated that, aside from equipment-related plant-to-plant variation in masa flow rates, no significant differences in masa flow rate means or variance across days were observed.

The dosifier flow-rates were also very uniform from day to day (Table II). Because of the consistency in the flow rates of the masa, very few dosifier adjustments were required beyond the initial setting on the first day of production. ANOVA results indicate that there was no significant day effect but there was a significant plant effect with dosifier flow rate. Because dosifier flow is adjusted to match masa flow and the grinding mills in the two plants were very different, the plant effect was expected. Of note is the greater flow rate variation in plant 1 , which turned out to be statistically significant. Equipment differences might account for this variation. The dosifiers in the two plants were manufactured approximately two years apart, with the plant 1 dosifier being newer but more extensively used before the study. Although the plant 1 dosifier variation was approximately double the plant 2 variation, it is still within acceptable limits.

\section{Fortification Consistency and Micronutrient Stability}

The variability of iron and zinc in $\mathrm{Ct}$ and MF tortillas within two different production runs on separate days is shown in Table III. Iron and sometimes zinc are commonly used as markers of premix addition in fortified foods, owing to the facility and reduced cost of mineral analysis. Both minerals were evaluated during the training period to determine whether one might be

TABLE II

Variation in Masa and Premix Flow Rates in Two Different Nixtamal Tortilla Plants over Four Days of Production ${ }^{\mathrm{a}}$

\begin{tabular}{|c|c|c|c|c|}
\hline \multirow[b]{2}{*}{ Sample Time ${ }^{b}$} & \multicolumn{2}{|c|}{ Masa Flow (kg/min) } & \multicolumn{2}{|c|}{ Premix Flow (g/min) } \\
\hline & Plant 1 & Plant 2 & Plant 1 & Plant 2 \\
\hline Day 1 & $n=5$ & $n=9$ & Not used ${ }^{b}$ & Not used \\
\hline Mean & 10.41 & 11.06 & & \\
\hline Maximum & 10.75 & 12.40 & & \\
\hline Standard deviation & 0.28 & 0.90 & & \\
\hline Day 2 & $n=6$ & $n=9$ & Not used & $n=10$ \\
\hline Standard deviation & 0.30 & 0.35 & & 0.19 \\
\hline Day 3 & $n=5$ & $n=9$ & $n=6$ & $n=10$ \\
\hline Mean & 11.29 & 11.27 & 11.26 & 11.18 \\
\hline Minimum & 11.05 & 10.48 & 10.80 & 11.00 \\
\hline Maximum & 11.55 & 12.45 & 11.51 & 11.40 \\
\hline Standard deviation & 0.22 & 0.69 & 0.26 & 0.14 \\
\hline
\end{tabular}

a Values represent individual samples collected at intervals over $8 \mathrm{hr}$ of production each day.

${ }^{\mathrm{b}}$ Only unfortified control masa was produced.

TABLE III

Mineral Levels in Control and Micronutrient-Fortified Nixtamal Tortillas and Fortified Corn Masa Flour Tortillas During Commercial Production Runs in Two Nixtamal Tortilla Plants ${ }^{\mathrm{a}}$

\begin{tabular}{|c|c|c|c|c|c|c|}
\hline \multirow[b]{2}{*}{ Treatment } & \multicolumn{2}{|c|}{ Plant 1} & \multicolumn{2}{|c|}{ Plant 2} & \multicolumn{2}{|c|}{ Masa Flour ${ }^{\mathbf{b}}$} \\
\hline & Zinc (mg/kg) & Iron (mg/kg) & Zinc (mg/kg) & Iron (mg/kg) & Zinc (mg/kg) & Iron $(\mathrm{mg} / \mathrm{kg})$ \\
\hline \multicolumn{7}{|l|}{ Control } \\
\hline Minimum & 20.76 & 25.41 & 17.89 & 27.29 & & \\
\hline Mean & $22.22 \mathrm{a}$ & $29.87 \mathrm{a}$ & $19.62 \mathrm{a}$ & $31.49 \mathrm{a}$ & & \\
\hline Standard deviation & 1.08 & 3.54 & 1.49 & 2.71 & & \\
\hline $\mathrm{CV}(\%)^{\mathrm{c}}$ & 4.9 & 11.8 & 7.6 & 8.6 & & \\
\hline Mean & $61.97 \mathrm{~b}$ & $120.99 b$ & $60.58 b$ & $117.75 b$ & 21.86 & 44.05 \\
\hline Standard deviation & 3.08 & 12.07 & 3.15 & 12.13 & 1.27 & 6.21 \\
\hline $\mathrm{CV}(\%)^{\mathrm{c}}$ & 5.0 & 10.0 & 5.2 & 10.3 & 5.8 & 9.4 \\
\hline
\end{tabular}

a Mineral levels $(\mathrm{db})$ in nixtamal tortilla samples ( $n=12$, per treatment) collected every 10 min during two 60-min production runs on separate days. Values followed by the same letter within columns are not significantly different $(P>0.05)$.

${ }^{\mathrm{b}}$ Flour tortilla data represent six batches of masa from each of two $\operatorname{lots}(n=12)$.

${ }^{\mathrm{c}}$ Coefficient of variation (standard deviation/mean). 
more consistent than the other and, therefore, more suitable as a marker. In every case, the CV for zinc was lower than that for iron and, in most cases, the CV for iron was nearly double that of zinc. Because both iron and zinc were measured simultaneously in the same ICP sample analysis, it is unlikely that differences in CVs between the two analytes were due to analytical variation. It appears that this variation is sample related. These results indicate that zinc may be a better marker for homogeneity testing during fortification trials with corn masa.

In addition to the expected variation in mineral content attributable to the fortification process and analytical variation, the iron and zinc content in raw corn varies from region to region and season to season (Maseca, personal communication). Other sources of variation include minerals potentially introduced from the millstones and lime and the process vessels and equipment. Also, some leaching and loss of minerals could occur during steeping, draining, and washing the nixtamal due to losses of mineral-rich pericarp, germ, and aleurone layer. The genetic variant of the corn, lime concentration, extent of cooking, and nixtamal washing are the main factors affecting removal of these anatomical parts (Serna Saldivar et al 1990). However, when considering differ-

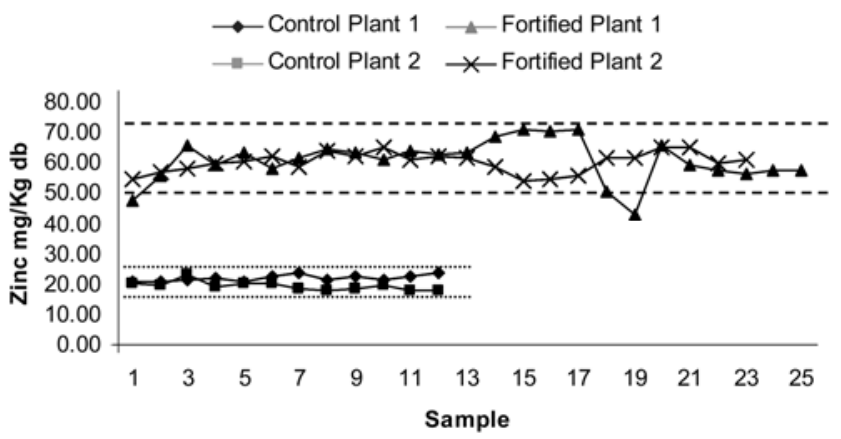

Fig. 1. Zinc levels in control and micronutrient-fortified tortillas sampled every 10 min during two (control) and four (fortified) 60-min production runs on separate days in two plants. (Dashed lines indicate $95 \%$ confidence limits.) ences in variation between $\mathrm{Ct}$ and $\mathrm{MF}$ tortillas produced the same day from the same lot of corn, the only factor that would be expected to differ between treatments within production runs is premix dosification. CV data in Table III indicate that the variation in mineral content in MF samples was no greater than the natural variation in unfortified $\mathrm{Ct}$ tortillas. Furthermore, micronutrient homogeneity in fortified nixtamal tortillas was also comparable with that in tortillas produced from fortified masa flour. These results are consistent with preliminary trials reported previously (Dunn et al 2007). Results of Table III also indicate little difference in homogeneity between plants, indicating that, despite the differing mill configurations, the fortification process appears to be consistent between plants.

Whereas Table III looks at homogeneity in many samples collected frequently during 60-min production runs, Table IV gives a sense of process variability from run to run across days. Again, the $\mathrm{CV}$ values were $5.9-10 \%$ for iron and zinc in both plants, which is acceptable given the many sources of variation. The dosing consistency and differentiation between $\mathrm{Ct}$ and MF samples are readily seen in Fig. 1, which displays zinc data and the corresponding 95\% confidence limits from samples collected during the initial week of training in each plant. The fact that data from plant 2 were collected after the experience gained from the week

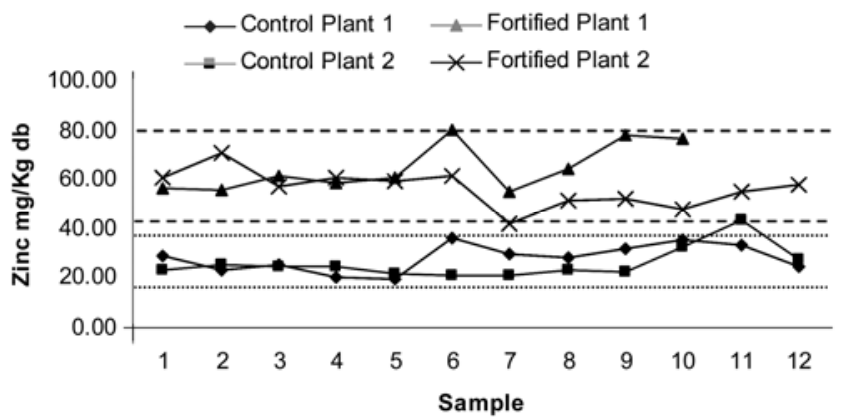

Fig. 2. Zinc levels in control and micronutrient-fortified tortillas over four weeks of commercial production in two plants. (Dashed lines indicate $95 \%$ confidence limits.)

TABLE IV

Variation in Zinc and Iron Levels (db) in Micronutrient-Fortified Tortillas Across Days ${ }^{\mathrm{a}}$

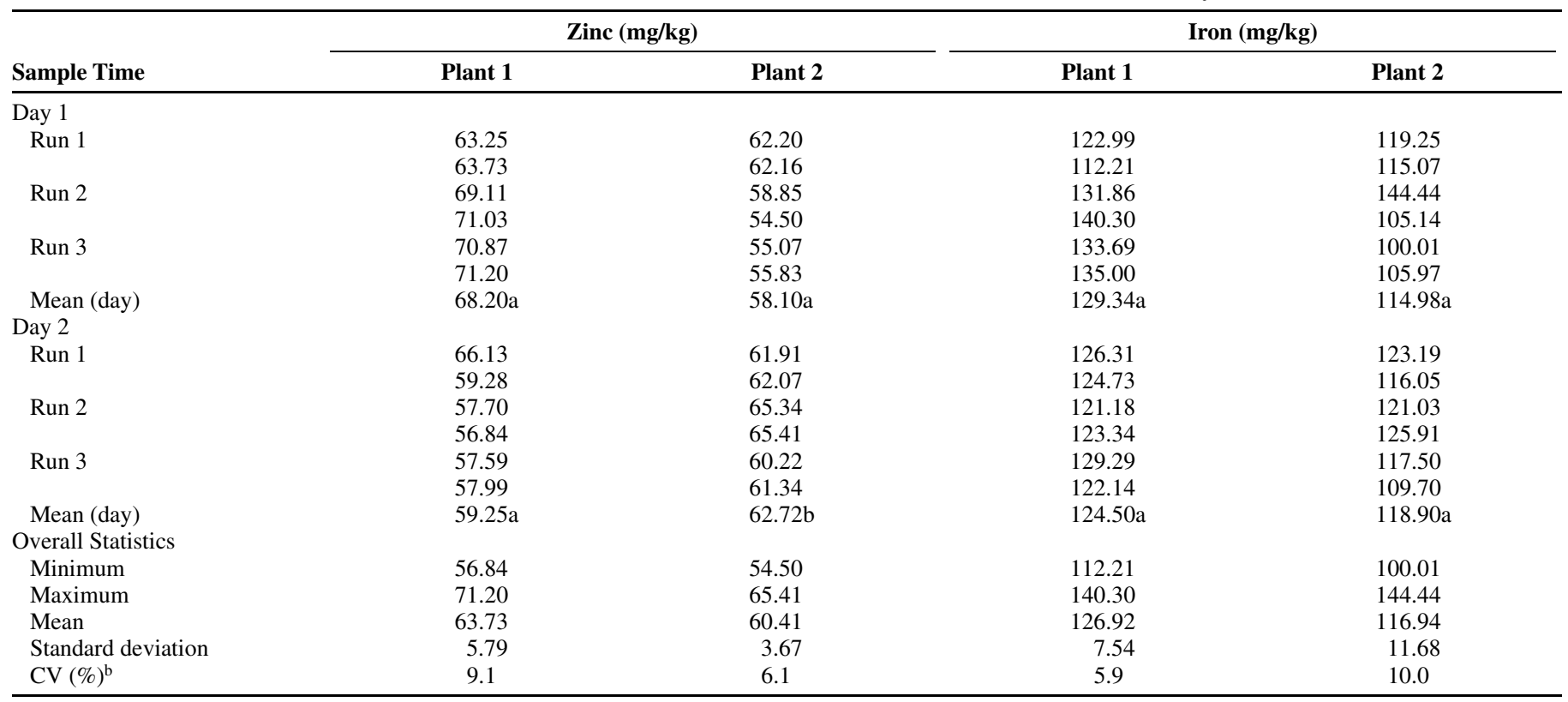

${ }^{a}$ Data represent individual values for duplicate samples collected from the midpoint of three different runs on two days. Values followed by the same letter within columns are not significantly different $(P>0.05)$.

${ }^{\mathrm{b}}$ Coefficient of variation (standard deviation/mean). 
of training in plant 1 is probably partially responsible for the more consistent appearance of the data from plant 2. The two data points below the lower control limit in the MF samples in Figure 1 are from samples taken at the beginning of a run following collection of control samples. It may be that some mixing of $\mathrm{Ct}$ and MF masa occurred with these samples. Overall, the dosification process appears to provide acceptable consistency in both plants and shows the capability for relatively good control when monitored appropriately.

\section{Commercial Production Evaluation}

After the one-week training period, each plant continued ongoing commercial production of fortified tortillas without further assistance from the project team. Figure 2 shows zinc levels in $\mathrm{Ct}$ and MF tortillas received from plants 1 and 2, respectively, from samples collected three days a week over the four-week period evaluated. Each data point on the graph represents a composite sample $(\approx 500 \mathrm{~g})$ collected at one time on a single day. The mineral data indicate that fortification consistency was quite good for the first two weeks of unaided production but there was significant variation on several days thereafter. Due to an error, only unfortified control samples were received from plant 1 on days 11 and 12. The increase in zinc in both control and fortified samples from plant 1 on day 6 might have resulted from either an analytical anomaly or an actual variation in the control corn. The quality control sheets show no apparent process anomalies that would account for the unusually high zinc values on sample days 6,9 , or 10 in plant 1 or for the unusually low reading on sample day 7 in plant 2. Because both mills were instructed to run control samples at the beginning of the day, it is almost certain that some mixing of $\mathrm{Ct}$ and MF masa would have occurred during the transition. This circumstance should not have affected the results unless the sample happened to be collected from this transitional masa. That this may have occurred is strongly indicated by the fact that $\mathrm{Ct}$ tortillas show some unusually high readings on days when no corresponding spikes are seen in MF samples. Other than this possible explanation, the millers noted no unusual circumstances other than a mill failure in plant 2 during the second week which required the primary mill to be offline for repairs during most of a day. The downward shift in the plot during the third week of production in plant 2 immediately follows this event but there is no specific explanation for this effect.

Although there was some variation in mineral content over the four-week production period evaluated, the overall appearance of the data is promising. This is especially so considering the shifting back and forth between control and fortified production.

\section{Micronutrient Stability}

Although a mechanically viable fortification process is critical to the success of this project, the most commonly expressed con- cern on the part of millers and those patronizing their establishments was that of micronutrient stability. Truly, a viable fortification process requires an adequate level of nutrient retention in the finished tortilla. To address this concern, two sets of fortified and unfortified tortilla samples were collected from successive days and analyzed for vitamin content by three external labs. Table $\mathrm{V}$ indicates that the vitamin content of the fortified tortillas was significantly improved, with nearly all vitamins showing excellent stability and large increases as a result of fortification. Due to these favorable increases, MF tortillas provided a significant percentage of the recommended daily intake of the key vitamins and minerals analyzed.

Although folic acid showed a nearly fivefold increase due to fortification, the final level in the tortilla was only $20 \%$ of theoretical estimates. The significant loss of folic acid in this commercial study was not surprising given that results from preliminary trials in the Guadalajara mill had indicated folic acid losses similar to though not as large as those reported here (Dunn et al 2007). However, folic acid stability was much higher in a previous study of commercially prepared, micronutrient-fortified nixtamal tortillas in the United States, where folate levels showed a ninefold increase after fortification (Burton et al 2008). Figueroa et al (2001) observed only a $36 \%$ loss of folate in a similar study. It was felt that one possible explanation for the disparity in folate results was the use of different analytical methods. The lab analyzing the samples for Burton et al (2008) used the AOAC microbiological assay for total folic acid (AOAC 960.46), whereas the folic acid results reported by Dunn et al (2007) were obtained from a laboratory using an HPLC method. The microbiological assay was again used in the current study, but this time with significant loss of folic acid. The fact that this loss was apparent in the unbaked masa indicates that the degradation occurred during milling or upon holding the masa prior to baking. A key formulation difference between the tortillas prepared in the study of Burton et al (2008) and those prepared during this study was the iron source and content. Burton used ferrous fumarate added at a level of $23.11 \mathrm{mg} / \mathrm{kg}$ of masa. In the current study, electrolytic iron was added at a level of $46.22 \mathrm{mg} / \mathrm{kg}$ of masa. The iron level was doubled to account for the lower bioavailability of electrolytic iron. Another potential difference between the studies was the masa holding time. Burton et al (2008) almost immediately transferred the masa from the mill to the tortilla forming/baking line, whereas the masa in the commercial mills in Mexico typically sat for up to $30 \mathrm{~min}$ before being made into tortillas and baked. Because masa was exiting the millstones at $52-58^{\circ} \mathrm{C}$, the additional holding time at this elevated temperature could have had an effect. However, this loss is still puzzling considering that Ball (2006) reports folic acid to be quite stable to heat and alkaline pH. Leskova et al (2006), on the other hand, found that folic acid is lost due to decomposition during extended

TABLE V

Micronutrient Content of Control and Fortified Masa and Tortillas ${ }^{a}$

\begin{tabular}{|c|c|c|c|c|c|c|}
\hline Treatment & Thiamin (mg/100g) & Riboflavin (mg/100g) & Niacin (mg/100g) & Folic Acid ( $\mu \mathrm{g} / \mathbf{1 0 0 g})$ & Zinc (mg/100g) & Iron $(\mathrm{mg} / 100 \mathrm{~g})$ \\
\hline Control masa & $0.40 \mathrm{a}$ & $0.10 \mathrm{a}$ & $1.78 \mathrm{a}$ & $11.54 \mathrm{a}$ & $2.78 \mathrm{a}$ & $2.82 \mathrm{a}$ \\
\hline Control tortilla & $0.41 \mathrm{a}$ & $0.11 \mathrm{a}$ & $2.31 \mathrm{~b}$ & $11.69 \mathrm{a}$ & $2.62 \mathrm{a}$ & $2.84 \mathrm{a}$ \\
\hline Fortified masa & $1.04 \mathrm{~b}$ & $0.43 b$ & $6.77 \mathrm{c}$ & $22.46 \mathrm{ab}$ & $7.31 \mathrm{~b}$ & $11.78 \mathrm{~b}$ \\
\hline Fortified tortilla & $1.07 \mathrm{~b}$ & $0.45 b$ & $6.66 \mathrm{c}$ & $56.20 \mathrm{~b}$ & $7.29 b$ & $12.24 \mathrm{c}$ \\
\hline Theoretical $^{\mathrm{b}}$ & 1.12 & 0.51 & 6.71 & 285.17 & 7.93 & 12.99 \\
\hline Theoretical (\%) & 95 & 89 & 99 & 20 & 92 & 94 \\
\hline $\operatorname{RDI}(\%)^{\mathrm{c}}$ & 36 & 14 & 17 & 14 & $2.4^{\mathrm{d}}$ & $4.1^{\mathrm{d}}$ \\
\hline $\mathrm{SEM}^{\mathrm{e}}$ & 0.03 & 0.02 & 0.12 & 8.75 & 0.14 & 0.11 \\
\hline
\end{tabular}

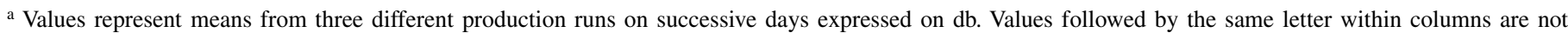
significantly different $(P>0.05)$.

b Theoretical value calculated by adding premix amount to levels in control tortilla.

${ }^{\mathrm{c}}$ Based on Mexican recommended daily intakes (RDI) in one 50-g serving (approximately two tortillas) per NOM-086-SSA1-1994 (Secretaria de Salud 1994).

d Based on $10 \%$ absorption estimate.

e Standard error of the mean. 
heating. Extended holding of hot masa before baking may result in the folate losses observed in this study. One interesting anomaly was the lower reported value for folic acid in the masa compared with baked tortilla. This result cannot readily be explained. Adding to the puzzle is the fact that one of the three labs could not provide folate results due to problems with analysis in these samples. The other two labs had similar results, however. Clearly, the loss of folic acid in this food matrix requires further study.

Iron is another important micronutrient for consideration due to the high levels of anemia present in the Mexican population. Corn is relatively low in iron and some of this is lost during nixtamalization, making tortillas poor sources of this mineral (Loy and Wright 2003). Furthermore, Reinhold et al (1984) reported that the fiber and zein (maize prolamins from endosperm) bound a substantial proportion of added ferrous and ferric iron at $\mathrm{pH} 6$ or higher but showed no such effect at $\mathrm{pH}$ lower than 5. Therefore, the addition of lime during nixtamalization diminishes the release of iron in tortillas. Tortilla iron levels in this study were increased significantly by fortification (Table V). These high iron levels result from addition of electrolytic iron at twice the targeted level of ferrous sulfate, owing to the lower bioavailability of this elemental iron source (Hurrell 1999).

Losses of thiamin (5\%), riboflavin (11\%), and niacin (1\%) in fortified tortillas were very low in this study compared with results reported by other scientists. Whereas niacin is typically considered a stable vitamin, the unusual stability of thiamin and riboflavin is encouraging. Bressani et al (1958) monitored changes in native thiamin, riboflavin, and niacin during processing of white and yellow corn tortillas. They reported losses of over $50 \%$ of thiamin, $30-50 \%$ of riboflavin, and approximately $30 \%$ of niacin during conversion to masa. Figueroa et al (2001) evaluated the addition of vitamins, minerals, and $4 \%$ defatted soybean meal in tortillas produced from fresh masa or from dry masa flour. Niacin, folic acid, thiamin, and riboflavin losses were approximately 29, 46,36 and $80 \%$, respectively. Riboflavin losses were attributed to lime cooking (64\% loss) and nixtamal washing (17\% loss). During nixtamal washing, losses of thiamin, riboflavin, and folic acid accounted for 18,17 , and $21 \%$, respectively. Burton et al (2008) reported virtually total loss of added thiamin during fortification of wet nixtamal in a batch process prior to milling. It appears that addition of micronutrients in the latter stages of the overall process results in minimal loss of labile vitamins other than folic acid.

\section{CONCLUSIONS}

The fortification system presented here appears to be a commercially viable means of fortifying nixtamal tortillas. Results of this study as well as previous research (Dunn et al 2007; Richins et al 2008) demonstrate that the method is easy to use, has minimal impact on the existing process, produces tortillas comparable with currently unfortified counterparts, and provides a dramatic improvement in nutrient content. Introduction of this technology in nixtamal mills throughout Mexico would have a significant impact on the nutritional well-being of those populations using the corn tortilla as a staple in the diet.

\section{ACKNOWLEDGMENTS}

This project was conducted in collaboration with SUSTAIN (www. sustaintech.org) through a grant to SUSTAIN from the Bill \& Melinda Gates Foundation. We wish to express gratitude to Todo de Maiz and Industria Alimentaria Cricotl for allowing the use of their tortillerias. We are also grateful to DSM Nutritional Products Mexico, Probst SA de CV, and Instituto Nacional de Salud Publica of Mexico, as well as representatives from COFEPRIS for their continuing involvement in this project.

\section{LITERATURE CITED}

AACC International. 2000. Approved Methods of the American Association of Cereal Chemists, 10th Ed. Methods 40-75, 44-31, 44-15, 4415A. The Association: St. Paul, MN.

AOAC. 2000. Official Methods of Analysis of the Association of Official Analytical Chemists International, 17th Ed. The Association: Gaithersburg, MD.

Ball, G. F. M. 2006. Folate. Pages 231-274 in: Vitamins in Foods. CRC Press: Boca Raton, FL.

Bressani, R., Paz y Paz, R., and Scrimshaw, N. S. 1958. Corn nutrient losses: Chemical changes in corn during preparation of tortillas. J. Agric. Food Chem. 6:770-773.

Burton, K. E., Steele, F. M., Jefferies, L, Pike, O. A., and Dunn, M. L. 2008. Effect of micronutrient fortification on nutritional and other properties of nixtamal tortillas. Cereal Chem. 85:70-75.

Dunn, M. L., Serna-Saldivar, S. O., and Turner, E. H. 2007. Industrial approaches to micronutrient fortification of traditional nixtamal tortillas. Cereal Foods World 52:240-248.

Figueroa, J. D. C. 1999. La tortilla vitaminada. Avance Perspectiva 18:149.

Figueroa, J. D. C., Godinez, M. G. A., Méndez, N. L. V., Guzmán, A. L., Acosta, L. M. F, and González-Hernández, J. 2001. Fortification and evaluation of nixtamalized tortillas. Arch. Latinoamericanos Nutr. 51:293-302.

Figueroa, J. D. C., Acero, G. M. G., Vasco, M. N. L., Lozano, G. A., and Flores, A. L. M. 2003. Nutritional quality of nixtamal tortillas fortified with vitamins and soy proteins. Int. J. Food Sci. Nutr. 54189-200.

Hurrell, R. F. 1999. Iron. Pages 54-93 in: The Mineral Fortification of Foods. R. F. Hurrell, ed. Leatherhead: London.

Leskova, E., Kubikova, J., Kovacikova, E., Kosicka, M., Porubska, J., and Holcikova, K. 2006. Vitamin Losses: Retention during heat treatment and continual changes expressed by mathematical models. J. Food Compos. Anal. 19:252-276.

Loy, D. D., and Wright, K. N. 2003. Nutritional properties and feeding value of corn and its by-products. Pages 571-603 in: Corn: Chemistry and Technology. P. J. White and L. A. Johnson, eds. Am. Assoc. Cereal Chem.: St. Paul, MN.

Reinhold, J. G., Garcia, P. M., and Garzon, P. 1984. Solubility of ferrous and ferric iron as affected by constituents of the maize tortilla. Nutr. Rep. Int. 30:603-615.

Richins, A. T., Burton, K. E., Pahulu, H. F. Jefferies, L, and Dunn, M. L. 2008. Effect of iron source on color and appearance of micronutrientfortified corn flour tortillas. Cereal Chem. 85:561-565.

Rosado, J. L., Camacho-Solis, R., and Borges, H. 1999. Adición de vitamina y minerales a harinas de maíz y de trigo en México. Salud Publica México 41:130.

Rosado, J. L., Cassís, L., Solano, L., and Duarte-Vázquez, M. A. 2005. Nutrient addition to corn masa flour: effect on corn flour stability, nutrient loss, and acceptability of fortified corn tortillas. Food Nutr. Bull 26:266-272.

Secretaria de Salud. 1994. Norma Oficial Mexicana NOM-086-SSA11994, Bienes y servicios. Alimentos y bebidas no alcoholicas con modificaciones en su composición. Especificaciones nutrimentales. $\mathrm{Pu}-$ blished online at http://www.cofepris.gob.mx/mj/documentos/ nom3.htm.

Secretaria de Salud. 2005. ANTEPROYECTO de Norma Oficial Mexicana PROY-NOM-000-SSA1-2005.

Serna-Saldivar, S. O., Gomez, M. H., and Rooney, L. W. 1990. The chemistry, technology and nutritional value of alkaline-cooked corn products. Chapter 4 in: Advances in Cereal Science and Technology, Vol. X. Y. Pomeranz, ed. AACC International: St. Paul, MN.

Shamah Levy, T., Avila Curiel, A., and Cuevas Nasu, L. 2003. The tortilla subsidy in Mexico: a nutritional or economic program? Arch. Latinoamericanos de Nutr. 53:5-13.

Tovar, L. R., and Larios-Saldaña, A. 2005. Iron and zinc fortification of corn tortilla made either at the household or at industrial scale. Int. J. Vitam. Nutr. Res. 75:142-148.

[Received March 31, 2008. Accepted August 22, 2008.] 